\title{
Comparison of nasal responsiveness to histamine, methacholine and phentolamine in allergic rhinitis patients and controls
}

\author{
R. GERTH VAN WIJK and P. H. DIEGES
}

Department of Allergology, University Hospital Dijkzigt, Rotterdam, The Netherlands

(Received in original form 8 January 1987 and in revised form 25 May 1987; accepted for publication 2 June 1987)

\begin{abstract}
Summary
In a selected group of rhinitis patients with an IgE-mediated allergy to house dust mites the nasal response to insufflation of histamine chloride, methacholine and phentolamine was demonstrated to be higher than in a control group. With the methods used histamine chloride was better at discriminating between healthy subjects and patients than methacholine or phentolamine. This discrimination was shown by assessing the severity of reflex-mediated symptoms such as the number of sneezes and the amount of secretion, and not by differences in nasal airway resistance.
\end{abstract}

\section{Introduction}

Non-specific hyperreactivity is a well-known phenomenon in bronchial asthma. Hyperreactivity is characterized by quantitative changes in the response of lung function to bronchial provocation with substances such as histamine or methacholine [1-3]. Although non-specific stimuli such as damp or changes of temperature can also induce nasal symptoms in rhinitis, there are no reliable tests to measure nasal hyperreactivity in an objective way [4]. Non-specific reactivity of the nose can be measured by means of nasal provocation tests with agents such as histamine and methacholine [4]. There is, however, no standard way of assessing the nasal response after provocation. In histamine provocation the increase in nasal airway resistance (NAR) is often used as a parameter of nasal response [5-7] but the number of sneezes [8] or even a 'tickling score' [9] has been used for this purpose.

Several explanations for nasal hyperreactivity are possible, such as increased mucosal permeability, changes in irritant receptors or reflex activity and changes in vessels and glands of the nasal mucosa [10]. The tendency for rhinitis patients to suffer

Correspondence: R. Gerth van Wijk, Department of Allergology, University Hospital Dijkzigt, Dr Molewaterplein 40, 3015 GD Rotterdam, The Netherlands. 
from nasal stuffiness could perhaps also be explained by a nasal $\alpha$-adrenergic dysfunction.

The aim of this study was two-fold. Originally, we tried to establish the best agent for discriminating between allergic rhinitis patients and healthy controls, using three provocative test agents: histamine, methacholine and phentolamine. The agents were chosen because of their different method of action on nasal mucosa. Histamine has an effect on both irritant receptors, thus stimulating nerves, and on vessels, thus causing nasal congestion [10]. Conversely, methacholine has a direct stimulating effect on glands [10] and phentolamine causes vasodilatation [11]. Secondly, we chose phentolamine, an alpha-receptor blocking agent, to investigate the $\alpha$-adrenergic responsiveness of the nasal mucosa.

\section{Subjects and methods}

\section{Study design}

Normal subjects and selected patients with a house dust mite (HDM) allergy underwent nasal provocation tests with histamine, methacholine and phentolamine (in this sequence) on separate days. The investigation period was restricted to 1 week for each patient. The group of healthy individuals was investigated during summer 1984 and the patients in September-November, this being the period with the highest number of house dust mites in Holland [12].

\section{Subjects}

Thirteen patients (six females, seven males), with perennial rhinitis that had lasted for more than 1 year, took part in the study. Their ages ranged from 19 to 31 with a median of 25 years.

Selection was based upon diagnosis of HDM allergy, confirmed by intradermal skin tests and radio-allergo-sorbent tests (RAST). With skin-test titration, positive reactions were found at low concentrations (1 Noon unit/ml). Specific IgE to HDM extract was high (class 3 or 4 ). None had previously received immunotherapy. Five patients had a pollen allergy and five also had an allergy to pets (without having pets in the house). Eighteen healthy students (nine females, nine males), without clinical signs and symptoms of rhinitis or asthma, participated in the study. Their ages ranged from 21 to 35 with a median of 25 years. None of the subjects had positive skin tests for a routine series of inhalant allergen extracts, neither had they specific IgE to HDM, grass pollen or cat dander, as measured with the RAST.

The study was approved by the Ethical Committee of the University Hospital and Medical Faculty, Erasmus University, Rotterdam. All participants gave their informed consent before taking part in the study.

\section{Agents}

Histamine chloride was used in the following concentrations: $0 \cdot 25,0 \cdot 5,1,2$, and $4 \mathrm{mg} /$ $\mathrm{ml}$; methacholine in the concentrations $8,16,32$, and $64 \mathrm{mg} / \mathrm{ml}$; phentolamine in the concentrations $1,2,4$, and $8 \mathrm{mg} / \mathrm{ml}$. The concentrations of phentolamine were chosen after consulting a cardiologist and taking into account the fact that nasal absorption of the drug is virtually complete. 


\section{Nasal provocation tests}

In the case of the patients, medication was withheld 2 days before the test. None of the subjects used topical corticosteroids or long-lasting antihistamines. Airway infections during the 2 weeks preceding the tests had been excluded.

On each occasion subjects waited half an hour before the test to allow the nasal mucosa to become acclimatized. After rhinoscopy a control solution (phosphate buffered saline containing human serum albumin $0.03 \%$ and benzalkonium chloride $0.05 \%$ ) was sprayed into the nostrils with a nasal pump spray delivering a fixed dose of $0.13 \mathrm{ml}$ solution. After provocation with the control solution, increasing doses of histamine chloride or methacholine or phentolamine were applied in both nostrils. The interval between each dose was $5 \mathrm{~min}$ in the case of histamine and $15 \mathrm{~min}$ in the case of methacholine and phentolamine.

After each provocation with histamine the subject was asked to bend forwards and to collect secretion in a syringe-equipped funnel, using the method introduced by Borum [13]. Sneezes were counted and just before the next provocation the NAR was measured three times. The median value was taken as the nasal airway resistance. When methacholine was used, secretion only was collected as methacholine has no effect on nasal resistance [13]. In the case of phentolamine the NAR was monitored. The nasal resistance of each nostril was measured using a passive anterior rhinomanometer (Heyer PAR) as previously described [14]. This entailed blowing an air stream with a fixed flow of $0.251 / \mathrm{sec}$ into each nostril. The resistance for the left $\left(R_{\mathrm{l}}\right)$ and the right $\left(R_{\mathrm{r}}\right)$ cavity were calculated by dividing the nasal pressure by the flow. The total nasal resistance was computed from the formula:

$$
R_{\mathrm{tot}}=R_{\mathrm{l}} \times R_{\mathrm{r}} /\left(R_{\mathrm{l}}+R_{\mathrm{r}}\right) .
$$

\section{Statistical analysis}

For paired observations the Wilcoxon signed rank test was used. For comparison of the patients and controls the Wilcoxon rank-sum test was used. A $P$ value of 0.05 or less was considered as statistically significant.

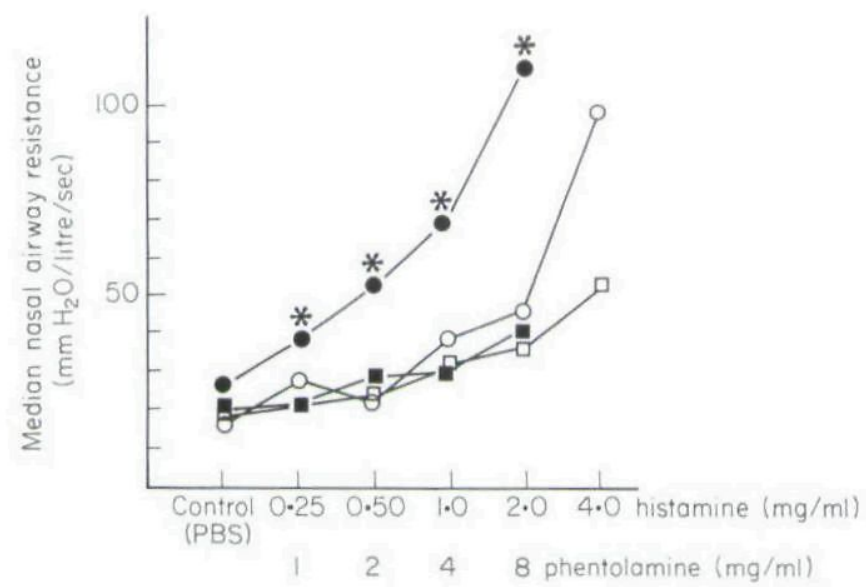

Fig. 1. Relationship between the concentration of both histamine (open symbols) and phentolamine (closed symbols) and the median nasal airway resistance for patients $(O$,

-) and controls $(\square, \mathbf{\square})$. The asterisk represents a significant higher response in patients than in controls (*: $P<0.05$ ). 


\section{Results}

Seventeen healthy subjects participated in the histamine provocation tests and eighteen in the methacholine and phentolamine tests. In the group of rhinitis patients thirteen histamine, twelve methacholine and eleven phentolamine provocation tests were done. One patient was withdrawn from the phentolamine provocation test because of dizziness. The three agents had different effects on the nose. Both histamine and phentolamine induced an increase in nasal resistance in the control and patient groups but only in the case of phentolamine was the nasal response higher in the patient group than in the control group (Fig. 1). No significant differences could be found in baseline NAR between patients and controls in either histamine or phentolamine provocation tests (Table 1). Both histamine and methacholine induced a higher secretory response in the patient group than in the control group (Fig. 2). In contrast, phentolamine had no effect on the nasal secretion. Histamine was capable of eliciting a sneeze reflex in the patient group (Fig. 3) whereas methacholine induced sneezes in only four patients and phentolamine caused no sneezes at all.

Significant side-effects of the nasal provocation tests were not seen. In the case of phentolamine one patient complained of dizziness during phentolamine provocation, however there was no objective change in pulse rate and blood pressure. Phentolamine used at a concentration of $8 \mathrm{mg} / \mathrm{ml}$ caused a transient painful burning sensation in the nose and so higher concentrations could not be used.

All median values plotted in Figs 1-3 represent a large range of individual values. In order to discriminate between patients and controls in a way that is easy to use in

Table 1. Initial baseline values of NAR* before provocation with histamine or phentolamine

\begin{tabular}{lllllll}
\hline & \multicolumn{2}{c}{ Histamine } & & \multicolumn{2}{c}{ Phentolamine } \\
\cline { 2 - 3 } \cline { 5 - 6 } & Controls & Patients & & Controls & Patients \\
& 18 & 19 & & 20 & 28 \\
Median & $12-25$ & $11-51$ & & $11-36$ & $14-52$ \\
$\begin{array}{l}\text { Range } \\
\text { Significance }\end{array}$ & & n.s. & & & \multicolumn{2}{c}{ n.s. } \\
\hline
\end{tabular}

* Expressed in $\mathrm{mm} \mathrm{H}_{2} \mathrm{O} /$ litre/sec.

clinical practice, we used an end-point titration method. Table 2 shows the histamine end-point concentrations using three different definitions of end-point. The median end-point concentrations required to double nasal resistance do not differ between the control and patient groups. In contrast, median end-point concentration needed to give $0.5 \mathrm{ml}$ secretion and/or five sneezes is eight times lower in the patient group than in the control group $(0.50$ vs $4 \mathrm{mg} / \mathrm{ml})$. A combination of symptoms does not enable a better distinction to be made between patients and controls.

A preliminary study of the variability of nasal provocation tests with histamine showed that the reproducibility of the test was better using the end-point concentrations required to produce $0.5 \mathrm{ml}$ secretion and/or five sneezes (to be published).

In the case of methacholine provocation the concentration needed to produce 0.5 $\mathrm{ml}$ secretion was at least $5 \cdot 6$ times lower in the patient group than in the control group ( 22.6 vs $128 \mathrm{mg} / \mathrm{ml}$ or more, $P<0.02$; Wilcoxon rank-sum test). 


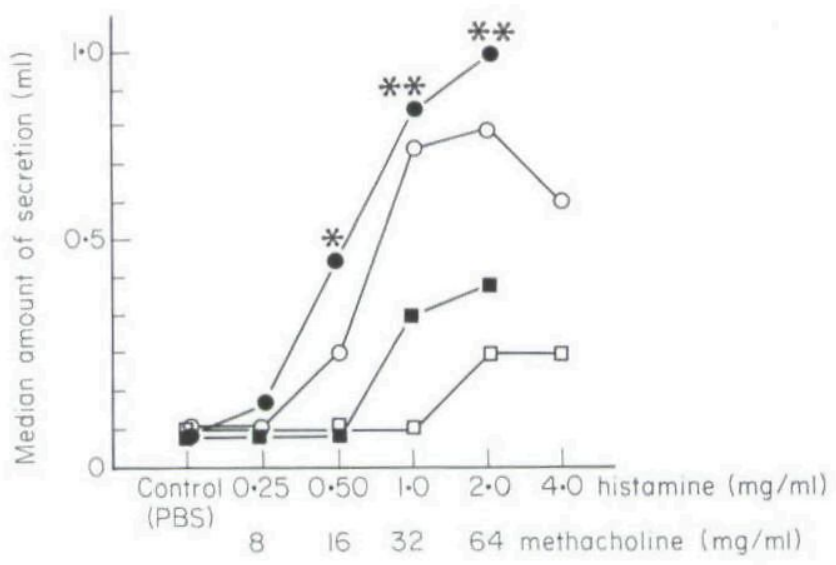

Fig. 2. Relationship between the concentration of both histamine (open symbols) and methacholine (closed symbols) and the median amount of secretion for patients $(O, \bullet)$ and controls $(\square, \mathbf{a})$. The asterisk represents a significant higher response in patients than in controls (*: $P<0.05 ; * *: P<0.01)$.

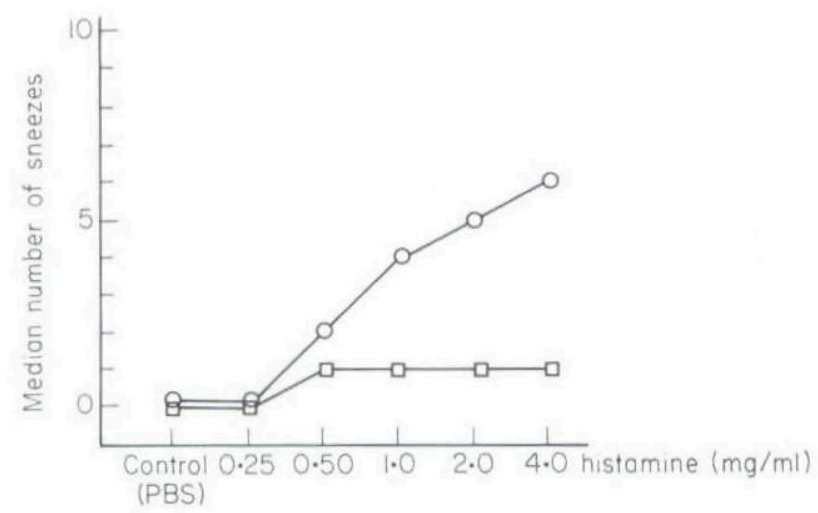

Fig. 3. Relationship between the concentration of histamine and the median number of sneezes. ( $\square$ ) Controls, (O) patients.

For phentolamine the concentration needed to double nasal resistance in the patient group ( 4 vs $8 \mathrm{mg} / \mathrm{ml}, P<0.05$; Wilcoxon rank sum test) was half that required for the controls.

\section{Discussion}

There are several studies of nasal response to non-specific stimuli [5-9, 13-20] but attempts to discriminate between patients and healthy subjects have lead to conflicting results $[6-8,13,15-18,20]$. The studies concerning nasal hyperreactivity differ from each other in the provocation technique, the way of assessing the symptoms and in selection of the patient population, which makes comparison of studies almost impossible. With our methods we observed a hyperresponsiveness to histamine, methacholine and phentolamine in allergic rhinitis patients. There are several possibilities that can explain the results. Firstly, increased permeability of the diseased mucosa may enable a better penetration of the test agents. Conversely, the observation 
Table 2. End-point concentration of histamine $(\mathrm{mg} / \mathrm{ml})$ in patients and controls.

\begin{tabular}{|c|c|c|c|c|c|c|c|c|}
\hline Histamine end-point concentration & 0.25 & 0.50 & 1.0 & $2 \cdot 0$ & $4 \cdot 0$ & $>4 \cdot 0$ & & \\
\hline \multirow{2}{*}{$\begin{array}{l}\text { Inducing } 100 \% \\
\text { increase in } \\
\text { nasal resistance }\end{array}$} & 2 & 1 & 7 & 1 & 0 & 6 & Controls $(n=17)$ & \multirow{2}{*}{$P>0.05$} \\
\hline & 2 & 1 & 4 & 5 & 0 & 1 & Patients $(n=13)$ & \\
\hline \multirow{2}{*}{$\begin{array}{l}\text { Inducing at least } 0.5 \mathrm{ml} \\
\text { secretion and/or } \\
\text { at least five sneezes }\end{array}$} & 1 & 2 & 2 & 2 & 4 & 6 & Controls & \multirow[t]{2}{*}{$P<0.05$} \\
\hline & 3 & 4 & 3 & 0 & 0 & 3 & Patients & \\
\hline \multirow{2}{*}{$\begin{array}{l}\text { Induring } 100 \% \text { increase in NAR, } \\
\text { and /or } 0.5 \mathrm{ml} \text { secretion and/or } \\
\text { five sneezes }\end{array}$} & 3 & 3 & 5 & 2 & 2 & 2 & Controls & \multirow[t]{2}{*}{$P>0.05$} \\
\hline & 4 & 4 & 4 & 1 & 0 & 0 & Patients & \\
\hline
\end{tabular}

that histamine has the same effect on the nasal resistance of patients and controls, suggests that a difference in permeability might be of minor importance. The fact that histamine leads to exaggerated secretory response and sneeze-reflex favours the second hypothesis, which is that the reflex-mediated activity in allergic patients is elevated.

A third possibility is that changes in glands and vessels are responsible for the observed hyperreactivity. The tendency to hyperresponsiveness to phentolamine could possibly reflect a defect in the $\alpha$-adrenergic system. Comparable assumptions have been made in bronchial asthma when using propanolol hyperresponsiveness as a measure of a defect in the $\beta$-adrenergic system. Our observation would correspond with the receptor-binding study of Ishibe et al. [21], who showed that there was a decrease in the number of alpha-1-adrenergic receptors in the nasal mucosa of patients with nasal allergy. However, we cannot exclude the possibility that the response to phentolamine may merely reflect a non-specific hyperreactivity. Another problem is that there was a slight, non-significant, difference in median baseline nasal resistance between patients and controls before provocation with phentolamine. This could theoretically influence the outcome of the tests.

The finding that histamine has an equal effect on nasal resistance in patients and controls conflicts with other studies [7, 8]. However, in our protocol the NAR was measured after a sometimes considerable amount of secretion had been collected in a syringe-equipped funnel. It could be that differences in nasal resistance measured after histamine provocation in other studies are due to a difference in the production of secretion. Another possible explanation is that measurement of total nasal resistance is less reliable in detecting differences than measurement of one-sided nasal resistance. In a recent study Corrado et al. [20] showed that only a few rhinitis patients allergic to Dermatophagoides pteronyssinus respond to histamine provocation with rhinorrhoea. In our study, however, patients were tested in autumn, as this is the season with the highest exposure to house dust mites. Recently we showed that nasal sensitivity to house dust mite and probably to histamine is increased in this season [22], perhaps due to a priming effect. The increased reflex mediated response found in our study could reflect the active state of the disease. 
To our knowledge no prospective studies of nasal hyperreactivity have been carried out in large unselected patient groups. Until this is done the importance of nasal provocation tests in daily clinical practice remains uncertain.

However, by using an end-point titration method this study provides a simple way of measuring nasal responsiveness and suggests that histamine is the best agent to use in nasal provocation tests to discriminate between normal subjects and allergic rhinitis patients with active disease, provided that the assessment of nasal response is focused on the reflex action of histamine (i.e. sneezes and secretion). The role of rhinomanometry in this test may be questioned. The results obtained with phentolamine provocation may reflect an $\alpha$-adrenergic dysfunction of the nasal mucosa.

\section{Acknowledgments}

We should like to thank Professor C. D. A. Verwoerd for critically reading the manuscript and Dr P. I. M. Schmitz for his statistical advice. We also thank Mrs E. Duyster for skilful technical assistance.

\section{References}

I De Vries K, Goei JT, Booij-Noord H, Orie NG. Changes during 24 hours in the lung function and histamine hyperreactivity of the bronchial tree in asthmatic and bronchitic patients. Int Arch Allergy Appl Immunol 1962; 20:93-101.

2 Townley RG, Ryo UY, Kolotkin BM, Kong B. Bronchial sensitivity to methacholine in current and former asthmatic and allergic rhinitis patients and control subjects. J Allergy Clin Immunol 1975; $56: 42942$.

3 Sanwikarya S, Schmitz PIM, Dieges PH. The effect of locally applied ipatropium acrosol on the nasal methacholine challenge in patients with allergic and non-allergic rhinitis. Ann Allergy 1986; 56:162 -6.

4 Mygind N, Borum P. Nasal provocation tests. In: Kerr JW, Ganderton MA, eds. Proceedings of the XI International Congress of Allergology and Clinical Immunology. London: Macmillan, 1983:207-12.

5 Britton MG, Empey DW, John GC. McDonnel KA. Hughes DTD. Histamine challenge and anterior nasal rhinometry: their use in the assessment of pseudoephedrine and trilodine as nasal decongestants in subjects with hayfever. Br J Clin Pharmacol 1978; 6:51-8.

6 Borum P. Reactivity of the nasal mucosa. In: Pepys J, ed. The Mast Cell. Bath: Pitman, 1979: $761-7$.

7 Clement PAR, Stoop AP, Kaufman L. Histamine threshold and nasal hyperreactivity in non specific allergic rhinopathy. Rhinology $1985 ; 23: 3542$.

8 Okuda M, Ohtsuka H. Sakaguchi K. Watase T. Nasal histamine sensitivity in allergic rhinitis. Ann Allergy $1983 ; 51: 51-5$.

9 Mygind N, Seher C, Kirkegaard J. Role of histamine and anti histamine in the nose. Eur J Respir Dis 1983:64 (suppl 128):16-20.

10 Mygind N. Mediators of nasal allergy. J Allergy Clin Immunol 1982: 70:149-59.

11 Wade A. Martindale the Extra Pharmacopeia. London: The Pharmaceutical Press, 1977.

12 Voorhorst R, Spieksma FTM, Varekamp H. House dust atopy and the house dust mite. Leiden: Stafleu's Scientific Publishing Co., 1969.

13 Borum P. Nasal methacholine challenge. J Allergy Clin Immunol 1979; 63:253-7.

14 Clement PAR, van Dishoeck EA, vd Wal EJ, Stoop AP, Hoeck GT, van Strik R. The nose provocation and the passive anterior rhinomanometry (P.A.R.). Acta oto-rhinolaryngol Belg 1978; 32:56-63.

15 McLean JA, Mathews KP. Solomon WR, Brayton PR, Ciarkowski AA. Effect of histamine and methacholine on nasal airway resistance in atopic and nonatopic subjects. J Allergy Clin Immunol 1977; 59:165-70.

16 McLean JA, Mathews KP, Brayton PR, Bayne NK. Effect of ammonia on nasal resistance in atopic and nonatopic subjects. Ann Oto Rhino Laryngol 1979; 88:228 34.

17 Druce HW, Wright RH, Kossow D, Kaliner MA. Cholinergic nasal hyperreactivity in atopic subjects. J Allergy Clin Immunol 1985; 76:445-52.

18 Tonnesen P. Mygind N. Nasal challenge with serotonin and histamine in normal persons. Allergy 1985; 40:350-3. 
19 Gronborg H, Borum P, Mygind N. Histamine and methacholine do not increase nasal reactivity. Clin Allergy 1986; 16:597-602.

20 Corrado OJ, Gould CAL, Kassab JY, Davies RJ. Nasal response of rhinitic and non-rhinitic subjects to histamine and methacholine: a comparative study. Thorax 1986; 41:863-8.

21 Ishibe T, Yamashita T, Kumazawa T, Tanaka C. Adrenergic and cholinergic receptors in human nasal mucosa in cases of nasal allergy. Arch Oto Rhino Laryngol 1983; 263:167-73.

22 Gerth van Wijk R, Dieges PH, van Toorenenbergen AW. Seasonal variability in nasal sensitivity to house dust mite extract. Rhinology 1987; 25:41-8. 
This document is a scanned copy of a printed document. No warranty is given about the accuracy of the copy. Users should refer to the original published version of the material. 